\title{
Avaliação citoquímica durante a germinação de sementes de sorgo envelhecidas artificialmente e osmocondicionadas, sob salinidade ${ }^{1}$
}

\author{
Cytochemical evaluation during the germination of artificial aged and primed \\ sorghum seeds under salinity
}

\author{
Alexandre Bosco de Oliveira ${ }^{2 *}$, Nara Lídia Mendes Alencar ${ }^{3}$, Maria Izabel Gallão e Enéas Gomes Filho $^{3}$
}

\begin{abstract}
Resumo - O objetivo desse trabalho foi avaliar as alterações citoquímicas em sementes envelhecidas e osmocondicionadas de sorgo durante a germinação na ausência ou presença de $\mathrm{NaCl}$ a $100 \mathrm{mM}$. O lote inicial de sementes de sorgo cv. IPA-1011 foi subdividido em dois sublotes de diferentes níveis de vigor, através do envelhecimento acelerado da metade das sementes, sendo a metade de cada sublote também submetida ao condicionamento osmótico em polietileno glicol 6000 a $-0,86 \mathrm{MPa}$ por 48 horas. Posteriormente, quatro subamostras de 50 sementes de cada um desses grupos de sementes foram postas sobre duas folhas de papel de filtro, saturadas com água destilada ou $\mathrm{NaCl}$ a $100 \mathrm{mM}$ e colocadas em caixas gerbox $(11 \times 11 \times 3,5 \mathrm{~cm})$ tampadas, as quais foram mantidas em câmara de germinação, sob escuro contínuo e temperatura de $25^{\circ} \mathrm{C}$, durante 72 horas. As análises citoquímicas foram feitas em sementes embebidas por 0; 24; 48 e 72 horas. As células das sementes de sorgo apresentaram formatos irregulares, variando de elíptico ao arredondado, sendo que a coloração com o azul de toluidina também revelou a presença de núcleos, principalmente em sementes osmocondicionadas, indicando que algumas células apresentaram intensa atividade celular. A presença de proteína foi detectada, principalmente em corpos protéicos no citoplasma das células cotiledonares, enquanto o amido foi identificado na forma de grânulos, principalmente no endosperma. Os tratamentos de envelhecimento acelerado e de osmocondicionamento das sementes, associados ao estresse salino, resultaram em pequenas alterações morfológicas e citoquímicas visíveis durante o período experimental.
\end{abstract}

Palavras-chave - Sorgo-sementes. Citoquímica. Sementes-morfologia. Estresse salino.

\begin{abstract}
The aim of this study was to evaluate the rate of water absorption and cytochemical changes in primed and aged seeds of sorghum during germination under absence or presence of $100 \mathrm{mM} \mathrm{NaCl}$. The initial batch of seeds of sorghum cv. IPA-1011, was divided into two batches of different levels of vigor, by the accelerated aging of half seeds, with half of each batch also referred to the priming of polyethylene glycol 6000 at $-0.86 \mathrm{MPa}$ for 48 hours. Four replicates of 50 seeds from each batch were placed on two sheets of filter paper, blotting paper saturated with distilled water and placed inside gerboxes $(11 \times 11 \times 3.5 \mathrm{~cm})$ transparent lids, which were kept in a germination chamber under continuous darkness and $25^{\circ} \mathrm{C}$ for 72 hours. The cytochemical analysis characterization was measured in the soaking times of $0 ; 24 ; 48$ and 72 hours. The sorghum seeds cells showed irregular shapes, ranging from elliptical to rounded, and the staining with the toluidine blue also revealed the presence of nuclei, especially in primed seeds, indicating that some cells showed high cellular activity. The presence of protein was detected mainly in protein bodies on cytoplasm of cotyledon cells, while the starch was identified in the form of granules at endosperm. The accelerated aging treatments and seed priming, associated to salt stress resulted in little morphological and cytochemical visible changes during the experimental period analyzed.
\end{abstract}

Key words - Sorghum-seeds. Cytochemical. Seeds-morphology. Salt stress.

\footnotetext{
* Autor para correspondência

${ }^{1}$ Recebido para publicação 06/05/2010; aprovado em 29/12/2010

Parte da tese de doutorado apresentada pelo primeiro autor no Programa de Pós-Graduação em Agronomia/Fitotecnia, Universidade Federal do Ceará ${ }^{2}$ Departamento de Fitotecnia, Área de Ecofisiologia da Germinação/UESPI, Uruçuí-PI, Brasil, aleufc@gmail.com

${ }_{3}^{3}$ Departamento de Bioquímica e Biologia Molecular, Área de Fisiologia Vegetal/UFC, Fortaleza-CE, Brasil, nlidi@yahoo.com.br, egomesf@ufc.br

${ }^{4}$ Departamento de Biologia, Área de Biologia Celular Vegetal/UFC, Fortaleza-CE, Brasil, edybel@ufc.br
} 


\section{Introdução}

A influência nociva dos sais na agricultura, apesar de se refletir diretamente na produção das culturas, se manifesta primeiramente na germinação. A salinidade diminui o potencial hídrico do meio, dificultando a absorção de água pela semente. Posteriormente, processos como os de divisão e alongamento celular, bem como o de mobilização das reservas, os quais são indispensáveis para a germinação, são também afetados (SOLTANI et al., 2006).

O processo germinativo constitui-se em uma fase crítica, influenciada por uma série de fatores em que há a necessidade da presença de um conjunto de condições favoráveis para que possa ser realizado de forma satisfatória (WINDAUER et al., 2007). Neste processo, a primeira etapa na seqüência de eventos que culminam com a retomada do crescimento do embrião é a embebição. A absorção de água pela semente dá início a uma série de processos físicos, fisiológicos e bioquímicos que, na ausência de fatores limitantes, resultam na emergência da plântula (MARCOS FILHO, 2005).

O controle da hidratação das sementes pode ser realizado através de diferentes métodos de condicionamento fisiológico das sementes, tais como o de embebição simples (mediante o equilíbrio com o vapor de água da atmosfera), o de embebição em substrato úmido, ou ainda podendo-se fazer a embebição por imersão direta das sementes em água. Além disso, o uso de substâncias químicas osmoticamente ativas como uma forma de controlar a entrada de água na semente é um método que tem sido amplamente difundido (HALMER, 2004). O agente osmótico mais comumente utilizado é o polietilenoglicol - PEG, em virtude do mesmo não ser fitotóxico, não atravessar o sistema de membranas e, portanto, não ser metabolizado pelas sementes (HONGBO et al., 2005).

Durante o condicionamento osmótico (ou priming) a semente hidrata-se lentamente, o que permite um maior tempo para a reparação ou reorganização das membranas plasmáticas, possibilitando a formação dos tecidos de maneira mais ordenada e reduzindo os riscos de danos ao eixo embrionário (McDONALD, 2000; WINDAUER et al., 2007). Alguns trabalhos na literatura relatam que o aumento no vigor de sementes osmocondicionadas ocorre em razão da eficiência desse tratamento em reparar a organização estrutural da membrana plasmática durante a embebição (CHIU et al., 2006).

Em razão do grande número de pesquisas visando melhorar a germinação das sementes sob condições adversas empregando tratamentos como os de osmocondicionamento ou de pré-hidratação
(ASHRAF; FOOLAD, 2005; PATANÈ et al., 2009), torna-se fundamental o conhecimento das alterações citoquímicas que ocorrem durante o processo germinativo nessas condições. Mudanças morfológicas nas sementes durante a germinação são normalmente acompanhadas por mudanças fisiológicas, e algumas dessas alterações metabólicas nos compostos de reserva podem ser detectadas in situ por meio de técnicas citoquímicas específicas (CORTELAZZO; VIDAL, 1991). Em soja, mudanças nos compostos de reserva foram detectadas in situ nos cotilédones durante a germinação (CORTELAZZO; VIDAL, 1991). Em jacarandá, resultados citoquímicos sugerem similar padrão de degradação das reservas de lipídios e proteínas durante a germinação e estabelecimento das plântulas (SILVA et al., 1997).

Considerando que o sorgo é um vegetal interessante para estudos de estresses abióticos e uma cultura com grande potencial de cultivo no semi-árido nordestino (OLIVEIRA; GOMES-FILHO, 2009), objetivou-se com esse trabalho caracterizar através de análises citoquímicas, a mobilização de reservas na germinação de sementes submetidas ou não ao envelhecimento precoce e/ou ao priming, sob condições controle e de estresse salino.

\section{Material e métodos}

O experimento foi conduzido no período de agosto a outubro de 2009, nos Laboratórios de Análise de Sementes e de Biologia Vegetal, pertencentes, respectivamente, aos Departamentos de Fitotecnia e de Biologia da Universidade Federal do Ceará (UFC), em Fortaleza, CE. Foram utilizadas sementes de sorgo granífero [Sorghum bicolor (L) Moench], cultivar IPA 1011, safra 2008, cedidas pela Empresa Pernambucana de Pesquisa Agropecuária (IPA), em Recife, PE. As referidas sementes encontravam-se armazenadas em frascos de vidro contendo sílica gel à temperatura de $8^{\circ} \mathrm{C}$.

O lote inicial de sementes foi dividido em dois sublotes: em um deles, as sementes foram submetidas ao envelhecimento acelerado de acordo com metodologia descrita por Oliveira (2010) para sementes de sorgo, as quais foram distribuídas numa camada única e uniforme sobre tela de alumínio fixada no interior de caixas plásticas transparentes de $11 \times 11 \times 3,0 \mathrm{~cm}$ (gerbox), com tampa, contendo no fundo $40 \mathrm{~mL}$ de água, mantidas em incubadora BOD a $43{ }^{\circ} \mathrm{C}$, sob umidade relativa do ar próxima de $100 \%$, por 72 horas; o outro sublote de sementes permaneceu sem tratamento (sementes não envelhecidas) e foi utilizado como controle. Após esse procedimento, a metade das sementes de cada um desses sublotes foi submetida ao tratamento de condicionamento osmótico. 
Para o condicionamento osmótico das sementes foi empregada a metodologia descrita por Patanè et al. (2009) para sementes de sorgo. Para tanto, as sementes foram colocadas em béqueres de $400 \mathrm{~mL}$ contendo 200 $\mathrm{mL}$ de solução de PEG-6000 a $250 \mathrm{~g} \mathrm{~L}^{-1}$ a qual, segundo Michel e Kaufmann (1973), corresponde a um potencial osmótico de $-0,86 \mathrm{MPa}$ a $15{ }^{\circ} \mathrm{C}$, quando permaneceram por 48 horas. Para a definição desse tempo foram feitas curvas de absorção de água das sementes envelhecidas e não envelhecidas, conforme metodologia descrita em Oliveira (2010).

O condicionamento osmótico foi conduzido em uma incubadora, sob escuro contínuo e aeração constante, a fim de garantir condições normais de respiração das sementes (BUJALSKI; NIENOW, 1991). Na parte inferior de cada béquer foi fixada uma mangueira estreita, com pedra porosa anexada na ponta, a qual se manteve conectada a uma pequena bomba de aquário, responsável pela insuflação de ar na solução. Após o condicionamento, as sementes foram cuidadosamente lavadas e, em seguida, secas com papel de filtro mata borrão, por 72 horas, em ambiente de laboratório. As sementes foram desinfetadas em solução de hipoclorito de sódio a $1 \%$, por cinco minutos e utilizadas nos experimentos.

Para a análise do processo germinativo sob condições controle ou de estresse salino, em diferentes períodos de embebição, quatro subamostras de aproximadamente quatro gramas de sementes de cada tratamento foram postas sobre duas folhas de papel de filtro mata borrão saturadas com água destilada (controle) ou solução de $\mathrm{NaCl}$ a $100 \mathrm{mM}$ (estresse salino) e colocadas no interior de caixas gerbox $(11 \mathrm{x}$ $11 \times 3,5 \mathrm{~cm}$ ) transparentes com tampas, as quais foram mantidas em câmara de germinação, sob escuro contínuo e temperatura de $25{ }^{\circ} \mathrm{C}$. Para os cortes histológicos, foram coletadas sementes com $0 ; 24 ; 48$ e 72 horas após a semeadura. $\mathrm{O}$ material coletado foi seccionado transversalmente e submetido à fixação em solução de paraformaldeído a $4 \%$ e glutaraldeído a $1 \%$ em tampão fosfato de sódio a $0,1 \mathrm{M}, \mathrm{pH} 7,2$, por 24 horas, sendo posteriormente mantidos a $4{ }^{\circ} \mathrm{C}$ (KARNOVSKY, 1965). Completado o tempo de fixação em solução de paraformaldeído/glutaradeído, o excesso de fixador foi removido através de três lavagens de 10 min cada com tampão fosfato a $0,1 \mathrm{M}, \mathrm{pH} 7,2$. Logo após, as amostras foram lavadas rapidamente com água destilada por três vezes. Posteriormente, as amostras foram expostas à desidratação em bateria crescente de etanol, iniciando com etanol a $40 \%$ e terminando com etanol a $100 \%$, com duração de 1 hora para cada solução. Após a desidratação, os cortes foram primeiramente préinfiltrados por embebição em resina-álcool etílico 1:1 por 24 horas. Em seguida, o material foi incluído em resina pura (Historesin Embbeding Kit - Jung). Ao final da preparação do material, foram feitos cortes seriados de $5 \mu \mathrm{m}$, em um micrótomo automático Leica RM 2065, os quais foram utilizados nas colorações.

O azul de toluidina é um corante metacromático utilizado para detectar radicais anionicos totais, tais como aqueles dos componentes da parede celular. A coloração com azul de toluidina (AT) a 0,025\%, $\mathrm{pH} 4,0$, ocorreu durante 15 minutos, à temperatura ambiente, sendo os cortes seguidamente submetidos à lavagens rápidas em água destilada e secagem ao ar livre (VIDAL, 1970). Ao final, os cortes foram montados entre lâmina e lamínulas em entelan.

O xylidine Ponceau (XP) é um corante utilizado para detectar radicais cationicos totais (VIDAL, 1977), tais como aqueles presentes nas proteínas, possibilitando a identificação de corpos protéicos. A solução de XP foi preparada a $0,1 \%$ em ácido acético glacial a $3 \%$, sendo o pH ajustado para 2,5. A coloração com XP foi realizada durante $15 \mathrm{~min}$ à temperatura ambiente, seguindo-se de lavagem em solução de ácido acético $3 \%$ por 15 minutos e duas lavagens rápidas em água destilada, secagem ao ar e montagem em entelan (CORTELAZZO; VIDAL, 1991).

A reação com lugol é utilizada para detecção de amido, possibilitando a identificação de grânulos de amido com uma coloração azul negra ou marrom muito escuro (BERLYN; MIKSCHE, 1976). A solução de lugol foi preparada na proporção de 1:1 (iodeto de potássio: iodo) dissolvidos em água destilada. Pingou-se uma gota da solução de lugol sobre os cortes incluídos em resina, que foram montados entre lâmina e lamínula em entelan, após o tempo de 5 minutos.

\section{Resultados e discussão}

A coloração com azul de toluidina(AT) foi utilizada para a análise morfológica das células cotiledonares das sementes de sorgo, em cortes transversais, nos quais foram verificados padrões semelhante de coloração em todas as condições analisadas (FIG. 1). Observaram-se paredes celulares finas coradas pelo AT, que não foram alteradas mesmo com os tratamentos de condicionamento osmótico, envelhecimento artificial e exposição ao sal. A coloração com azul de toluidina também revelou paredes celulares finas das células cotiledonares de Moringa oleifera, em trabalho realizado por Gallão et al. (2006). Em cotilédones de sementes quiescentes de Phaseolus vulgaris, foram observados elementos aniônicos corados no citoplasma, bem como paredes celulares corados com AT (CORTELAZZO et al., 2005). 

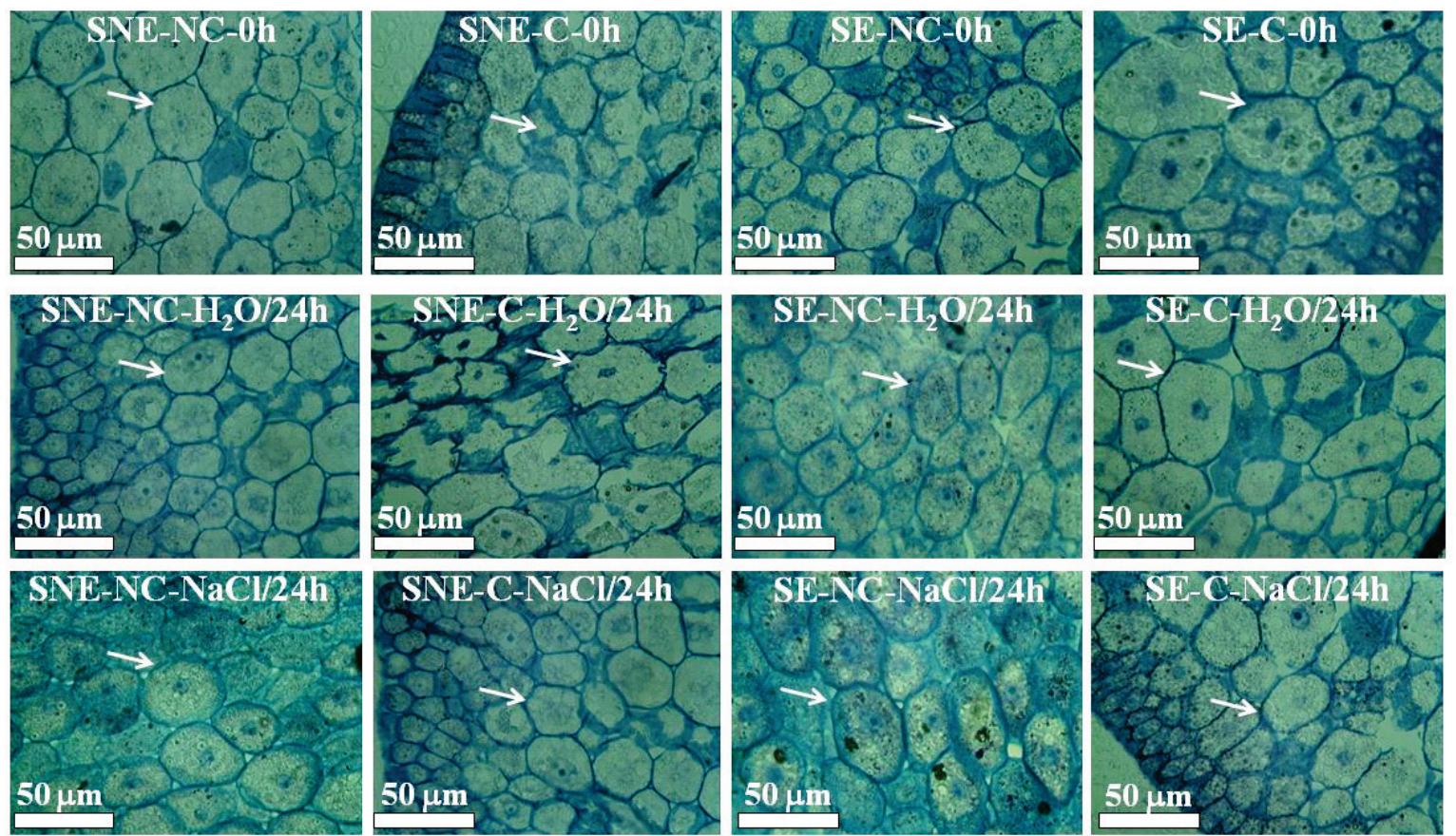

Figura 1 - Cortes transversais de sementes de sorgo coradas com o azul de toluidina, evidenciando a parede celular e o formato das células $(\rightarrow)$. SNE - semente não envelhecida; SE - semente envelhecida; NC - semente não condicionada; C - semente condicionada; $0 \mathrm{~h}$ - semente quiescente; $\mathrm{H} 2 \mathrm{O} / 24 \mathrm{~h}$ - semente embebida em água por $24 \mathrm{~h} ; \mathrm{NaCl} / 24 \mathrm{~h}$ - semente embebida em solução de $\mathrm{NaCl}$ a $100 \mathrm{mM}$ por $24 \mathrm{~h}$

As células apresentaram formatos irregulares, variando do elíptico ao arredondado (FIG. 1). Os cortes que apresentaram maior variação no formato e tamanho da célula foram os das sementes envelhecidas e osmocondicionadas, seja na semente quiescente, ou com 24 horas de embebição na ausência e na presença de $\mathrm{NaCl}$. A coloração pelo AT também revelou a presença de núcleos, indicando que algumas células apresentavam intensa atividade celular, o que pode ser relacionado ao osmocondicionamento das sementes, uma vez que os tratamentos que envolviam as sementes de qualquer nível de qualidade fisiológica (envelhecida ou não) submetidas ao condicionamento osmótico e embebidas em água destilada apresentaram os núcleos corados mais intensamente (FIG. 1). Portanto, os resultados obtidos corroboram em parte com aqueles encontrados por Lanteri et al. (1996), os quais relataram em sua pesquisa que o condicionamento osmótico de sementes de pepino não submetidas ao envelhecimento artificial induziu as células embrionárias a entrarem na fase de síntese de DNA e, por conseguinte, aumentarem a taxa de multiplicação celular. Estudos bioquímicos indicam que o metabolismo do RNA e a síntese de proteínas também são aumentados pelo condicionamento osmótico, sugerindoque este tratamento deixa disponível às sementes, precursores utilizados para a síntese de macromoléculas (HALMER, 2004; McDONALD, 2000). Concordando com os dados obtidos no presente estudo, outros trabalhos na literatura têm relatado que, sob condições de alta umidade e alta temperatura proporcionadas pelo envelhecimento acelerado, o condicionamento com PEG-6000 proporciona melhor desempenho das sementes em relação à testemunha, como observado por Medeiros Filho et al. (2000) e por Kikuti et al. (2005) em sementes de sorgo e de pimentão, respectivamente.

As análises citoquímicas com o corante xylidine Ponceau (XP) detectaram a presença de proteínas no citoplasma das células cotiledonares das sementes de sorgo, armazenadas em vacúolos de reserva, sendo observadas poucas alterações nessas células nos diferentes tratamentos analisados (FIG. 2). Esses corpos protéicos se apresentavam como corpúsculos globulares com pequenas dimensões, distribuídos por todo o citoplasma. A presença de muitos corpúsculos globulares, intensamente corados por XP, também foi observada no citoplasma das células cotiledonares de Cesalpinia peltophoroides (CORTE et al., 2006) e Prosopis juliflora (GALLÃO et al., 2007). 

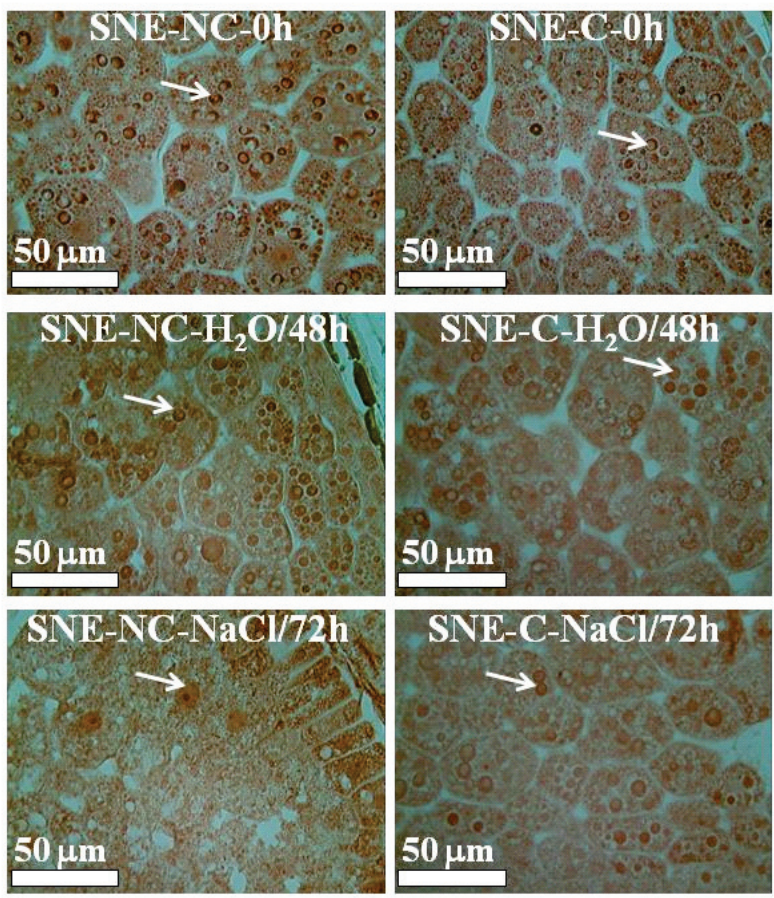
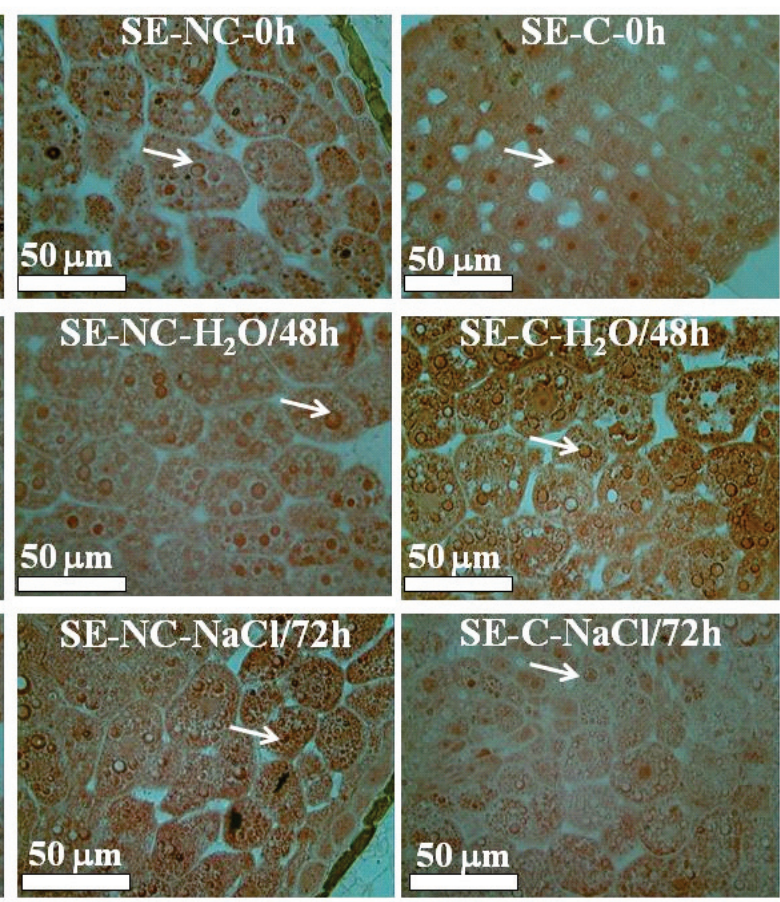

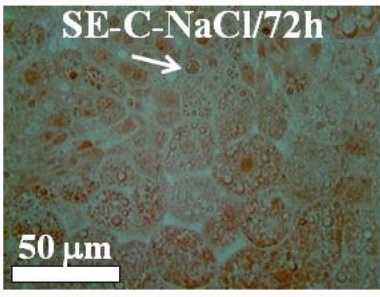

Figura 2 - Cortes transversais de sementes de sorgo coradas com o xylidine ponceau, evidenciando os corpos protéicos nas células cotiledonares $(\rightarrow)$. SNE - semente não envelhecida; SE - semente envelhecida; NC - semente não condicionada; $\mathrm{C}$ - semente condicionada; $0 \mathrm{~h}$ - semente quiescente; $\mathrm{H} 2 \mathrm{O} / 48 \mathrm{~h}$ - semente embebida em água por $48 \mathrm{~h} ; \mathrm{NaCl} / 72 \mathrm{~h}$ - semente embebida em solução de $\mathrm{NaCl}$ a $100 \mathrm{mM}$ por $72 \mathrm{~h}$

Observou-se pequena redução do número de corpos protéicos nos cortes das sementes envelhecidas e osmocondicionadas, tanto nas quiescentes, como nas embebidas por 72 horas em solução salina (FIG. 2). Tal efeito pode ter sido causado pelo envelhecimento artificial das sementes de sorgo, uma vez que, de maneira semelhante, Cortelazzo et al. (2005), avaliando as alterações citoquímicas em cotilédones das sementes de Phaseolus vulgaris submetidas ao envelhecimento acelerado, observaram a perda do conteúdo protéico e uma maior desorganização desses glóbulos quando comparado às sementes frescas e submetidas ao armazenamento.
As células do endosperma praticamente não foram coradas pelo XP (FIG. 3), podendo tal comportamento estar relacionado com o fato de que essa região possui como fonte principal de reserva o amido, o que é confirmado pela intensa coloração da região endospermática das sementes de sorgo com o lugol (FIG. 4 e 5). Gallão et al. (2006) obtiveram resultados contrastantes ao obtido neste ensaio, os quais relataram pouca quantidade de amido detectada na análise morfológica de sementes de moringa. No entanto, segundo esses autores, é possível que o amido não tenha sido detectado devido à grande quantidade de proteína presente no endosperma, impedindo sua visualização.
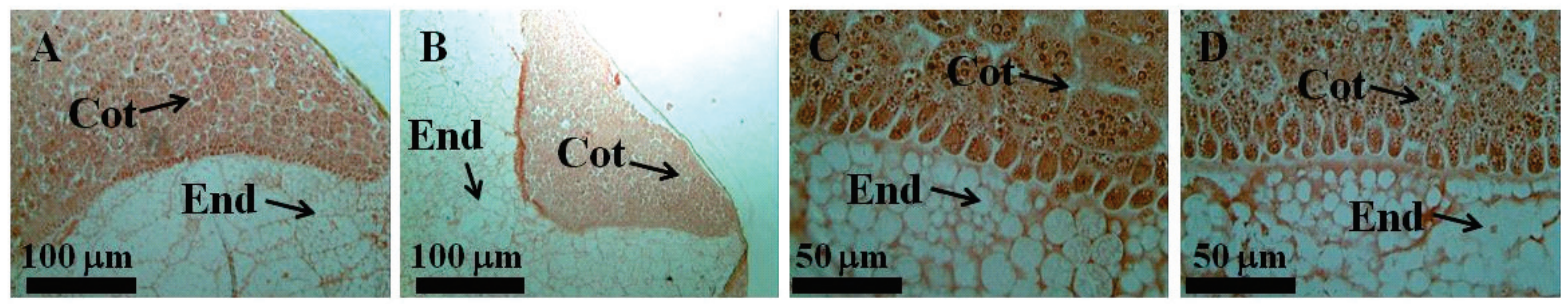

Figura 3 - Cortes transversais de sementes de sorgo coradas com o xylidine ponceau, evidenciando $(\rightarrow)$ a região endospermática (End) e cotiledonar (Cot). Semente quiescente submetida (B e D) ou não (A e C) ao envelhecimento artificial 
Endosperma
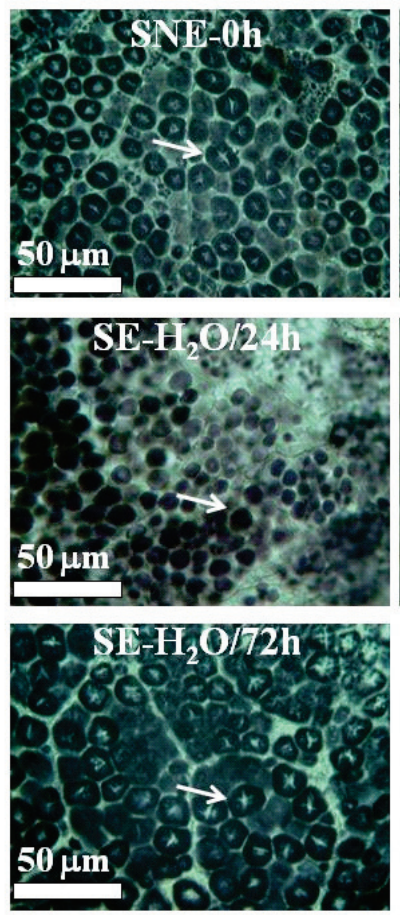

Cotilédone
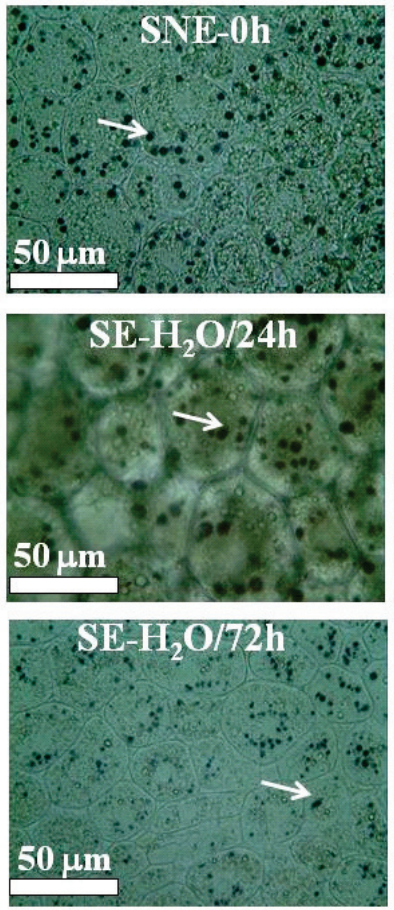

Endosperma
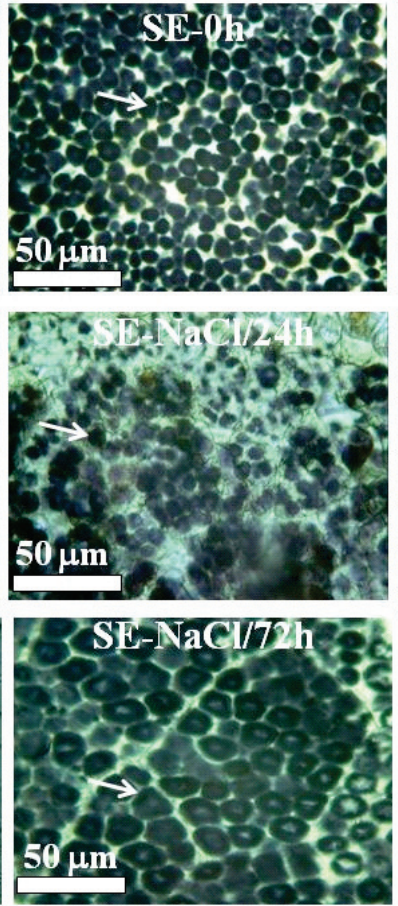

Cotilédone
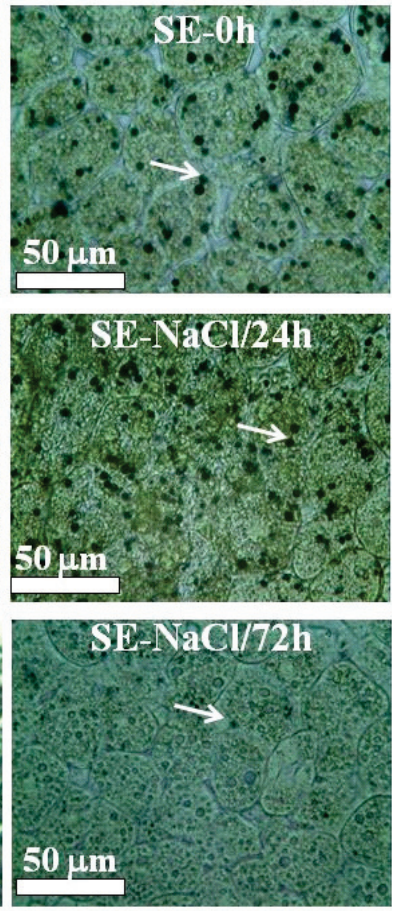

Figura 4 - Cortes transversais de sementes de sorgo coradas com lugol. Endosperma e cotilédone das sementes, evidenciando os grânulos de amido $(\rightarrow)$. SNE - semente não envelhecida; SE - semente envelhecida; 0h - semente quiescente; H2O/24h - semente embebida em água por $24 \mathrm{~h}$; NaCl/24h - semente embebida em solução de $\mathrm{NaCl}$ a $100 \mathrm{mM}$ por 24 h. H2O/72h - semente embebida em água por $72 \mathrm{~h} ; \mathrm{NaCl} / 72 \mathrm{~h}$ - semente embebida em solução de $\mathrm{NaCl}$ a $100 \mathrm{mM}$ por $72 \mathrm{~h}$

Os cortes transversais das sementes de sorgo coradas com lugol evidenciaram no endosperma e nos cotilédones a presença de grânulos de amido no citoplasma dessas células (FIG. 4). Entretanto, observou-se um padrão de coloração diferenciado entre os tecidos da semente, sendo que o endosperma apresentou abundante quantidade de grânulos de amido com formato arredondado, intensamente corados pelo lugol, preenchendo todo o citoplasma das suas células. Essa grande quantidade de amido detectada nas sementes de sorgo através da coloração com o lugol corrobora com Antunes et al. (2007), os quais avaliaram 33 genótipos de sorgo e verificaram que os teores de amido variaram de 62,07 a 78,74\%, sendo, portanto, o amido a principal reserva do grão de sorgo.

No endosperma, não foram verificadas diferenças marcantes no tamanho dos grânulos de amido em virtude dos tratamentos realizados, isto é, do envelhecimento artificial e condicionamento osmótico das sementes, bem como, da exposição das mesmas ao sal, indicando que essa reserva se manteve praticamente constante, mesmo sob condição de estresse salino. Uma exceção a esse comportamento ocorreu para os tratamentos com a semente não osmocondionada e osmocondicionada com
$48 \mathrm{~h}$ de exposição ao sal, onde foi verificada redução do número dos grânulos de amido dessas células (FIG. 5). Resultados divergentes foram obtidos por Silva et al. (2008) em sementes de trigo, os quais observaram que os teores de amido da semente aumentaram em função da exposição das mesmas ao estresse salino.

Com relação aos cotilédones, as suas células também revelaram coramento positivo do citoplasma com lugol, entretanto, diferentemente do endosperma, os grânulos de amido se apresentaram em menor número, com dimensões muito menores do que os observados no endosperma, com formato semelhante a pontos escuros (FIG. 4 e 5). Adicionalmente, nos cotilédones, observou-se também redução no número desses grânulos, especialmente nos tratamentos com sementes envelhecidas, após 24 (FIG. 4F) e 72 horas de embebição em água destilada (FIG. 4J) e em presença de $\mathrm{NaCl}$ (FIG. 4L), bem como na semente osmocondicionada germinando sob estresse salino (FIG. 5J). Durante a formação das substâncias de reserva das sementes de Bixa orellana, os grânulos de amido se apresentavam pequenos e em pequena quantidade, porém, com o avanço da maturação das sementes, estes 
Endosperma
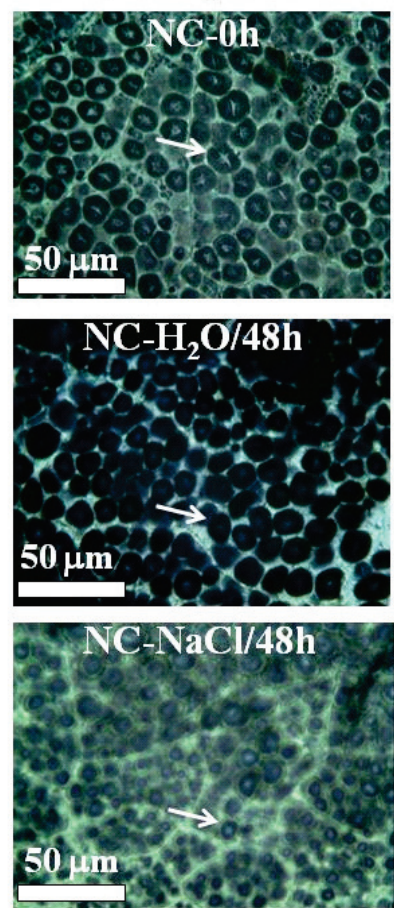

Cotilédone
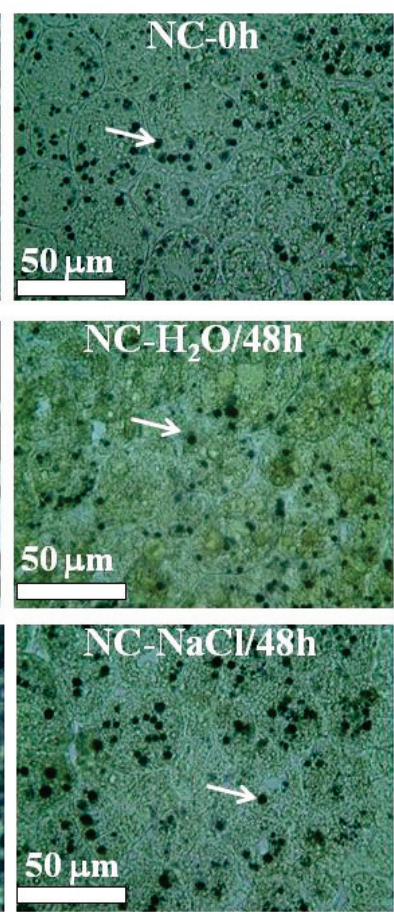

Endosperma
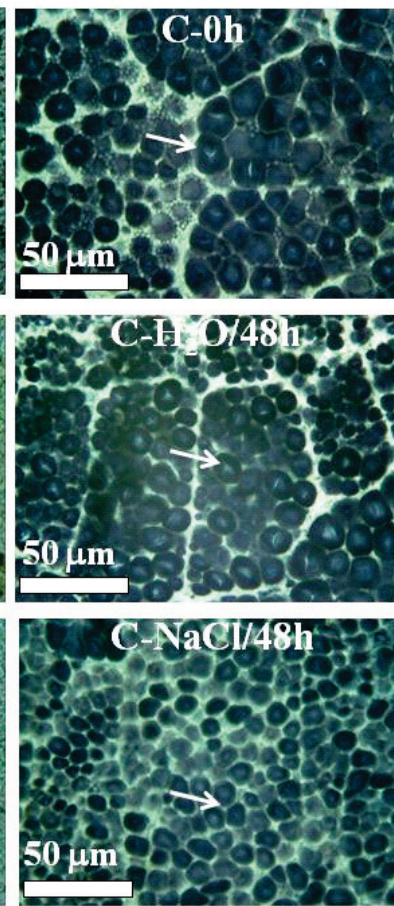

Cotilédone
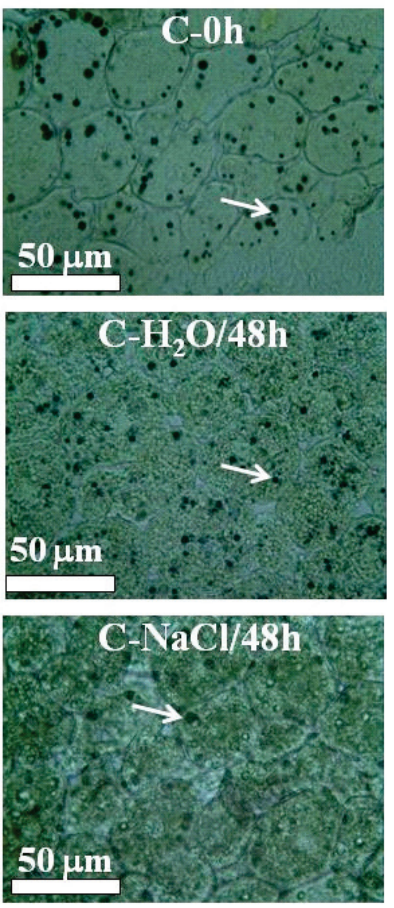

Figura 5 - Cortes transversais de sementes de sorgo coradas com lugol. Endosperma e cotilédone das sementes, evidenciando os grânulos de amido $(\rightarrow)$. NC - semente não condicionada; C - semente condicionada; 0h - semente quiescente; H2O/48h semente embebida em água por $48 \mathrm{~h} ; \mathrm{NaCl} / 48 \mathrm{~h}$ - semente embebida em solução de $\mathrm{NaCl}$ a $100 \mathrm{mM}$ por $48 \mathrm{~h}$

adquiriram formato arredondado e se apresentavam em maior número. Por outro lado, durante a germinação das sementes, foi observada redução do número dos grânulos de amido e mudança no seu formato devido à sua mobilização durante o desenvolvimento da nova plântula (AMARAL et al., 2001).

O amido é uma das mais importantes formas de reserva de carbono nas plantas, em termos de quantidade, universalidade de sua distribuição e importância comercial (ANTUNES et al., 2007). Teixeira e Machado (2008), estudando a localização das reservas de Caesalpinia echinata e Caesalpinia ferrea, observaram que o amido é a principal reserva que se acumula nas células dos tecidos de reserva dessas espécies. Em Prosopis juliflora, os grânulos de amido aumentaram até $24 \mathrm{~h}$ de embebição da semente, diminuindo logo em seguida após 72 horas (GALLÃO et al., 2007). Nas sementes de Phaseolus vulgaris, submetidas ao envelhecimento acelerado, observou-se perda do conteúdo celular e decréscimo do diâmetro dos grânulos de amido quando comparado às sementes secas e estocadas (CORTELAZZO et al., 2005). De forma discordante, por não ter sido observado grandes alterações na morfologia das sementes de sorgo, mesmo quando expostas as condições de estresse, pode-se dizer que estas não sofreram danos morfológicos que pudessem comprometer os componentes de reserva de suas sementes.

\section{Conclusões}

1. As células das sementes de sorgo apresentaram formatos irregulares, variando do elíptico ao mais arredondado, sendo que a coloração com o azul de toluidina também revelou a presença de núcleos, principalmente em sementes osmocondicionadas, indicando que algumas células apresentaram intensa atividade celular;

2. As proteínas foram detectadas, principalmente, em corpos protéicos nos cotilédones, enquanto que o amido foi identificado na forma de grânulos, principalmente no endosperma;

3. O envelhecimento artificial e o condicionamento osmótico, bem como a exposição destas ao estresse salino, resultaram em poucas mudanças morfológicas e citoquímicas. 


\section{Referências}

AMARAL, L.I.V.;PEREIRA, M.F.D. A.; CORTELAZZO, A.L. Formação das substâncias de reserva durante o desenvolvimento de sementes de urucum (Bixa orellana 1. - Bixaceae). Acta Botanica Brasílica, v. 15, n. 01, p. 125-132, 2001.

ANTUNES, R. C. et al. Composição bromatológica e parâmetros físicos de grãos de sorgo com diferentes texturas do endosperma. Arquivos Brasileiros de Medicina Veterinária e Zootecnia, v. 59, n. 05, p. 1351-1354, 2007.

ASHRAF, M.; FOOLAD, M. R. Pre-sowing seed treatment - A shotgun approach to improve germination, plant growth, and crop yield under saline and non-saline conditions. Advances in Agronomy, v. 88, n. 03, p. 223-271, 2005.

BERLYN, G. P.; MIKSCHE, J. P. Botanical microtechnique and cytochemistry. Ames: Iowa State University, 1976. p. 121-276.

BUJALSKI, W.; NIENOW, A.W. Large-scale osmotic priming of onion seeds: a comparison of different strategies for oxygenation. Scientia Horticulturae, v. 46, n. 01/02, p. 13-24, 1991.

CHIU, K. Y.; CHUANG, S. J.; SUNG, J. M. Both antioxidation and lipid-carbohydrate conversion enhancements are involved in priming-improved emergence of Echinacea purpurea seeds that differ in size. Scientia Horticulturae, v. 108, n. 02, p. 220-226, 2006.

CORTE, V. B. et al. Mobilização de reservas durante a germinação das sementes e crescimento das plântulas de Caesalpinia peltophoroides Benth. (Leguminosae-Caesalpinoideae). Revista Árvore, v. 30, n. 06, p. 941-949, 2006.

CORTELAZZO, A. L.; VIDAL, B. C. Soybean seed proteins: Detection in situ and mobilization during germination. Revista Brasileira de Botânica, v. 14, n. 01, p. 27-33, 1991.

CORTElazZO, A. L.; COUTINHO, J.; GRANJEIRO, P. A. Storage and ageing of french beans (Phaseolus vulgaris L.): Effect on seed viability and vigor. Brazilian Journal Morphology Science, v. 22, n. 02, p. 121-128, 2005.

GALLÃO, M. I.; DAMASCENO, L. F.; BRITO, E. S. Avaliação química e estrutural da semente de moringa. Revista Ciência Agronômica, v. 37, n. 01, p. 106-109, 2006.

GALLÃO, M. I. et al. Reserve mobilisation in mesquite (Prosopis juliflora) seed (Leguminosae). Journal of the Science of Food and Agriculture, v. 87, n. 11, p. 2012-2018, 2007.

HALMER, P., Methods to improve seed performance in the field. In: BENECH-ARNOLD, R. L.; SANCHEZ, R. (Ed.), Handbook of Seed Physiology. New York: Food Product Press, 2004. p. 125-156.

HONGBO, S. et al Impacts of PEG-6000 pretreatment for barley (Hordeum vulgare L.) seeds on the effect of their mature embryo in vitro culture and primary investigation on its physiological mechanism. Colloids and Surfaces B: Biointerfaces, v. 41, n. 02/03, p. 73-77, 2005.
KARNOVSKY, M. J. A formaldehyde-glutaraldehyde fixative of high osmolarity for use in electron microscopy. Journal of Cell Biology, v. 27, n. 04, p. 137-142, 1965.

KIKUTI, A. L. P.; KIKUTI, H.; MINAMI, K. Condicionamento fisiológico em sementes de pimentão. Revista Ciência Agronômica, v. 36, n. 02, p. 243-248, 2005.

LANTERI, S.; NADA, E.; BELLETTI, P. Effects of controlled deterioration and osmoconditioning on germination and nuclear replication in seeds of pepper (Capsicum annuиm L.). Annals of Botany, v. 77, n. 66, p. 591-597, 1996.

MARCOS FILHO, J. Fisiologia de sementes de plantas cultivadas. Piracicaba: FEALQ, 2005. 495 p.

MEDEIROS FILHO, S. et al. Efeito do condicionamento no vigor de sementes de sorgo. Revista Ciência Agronômica, v. 31, n. 01/02, p. 33-42, 2000.

McDONALD, M. B. Seed priming. In: BLACK, M., BEWLEY, J.D. (Ed.), Seed Technology and Its Biological Basis. Sheffield: Sheffield Academic Press, 2000. p. 287-325.

MICHEL, B. E.; KAUFMANN, M. R. The osmotic potential of polyethylene glycol 6000. Plant Physiology, v. 51, n. 06, p. 914-916, 1973.

OLIVEIRA, A. B.; GOMES-FILHO, E. Germinação e vigor de sementes de sorgo forrageiro sob estresse hídrico e salino. Revista Brasileira de Sementes, v. 31, n. 03, p. 48-56, 2009.

OLIVEIRA, A. B. Envelhecimento artificial, osmocondicionamento e estresse osmótico em sementes de sorgo: parâmetros fisiológicos, bioquímicos e citoquímicos. 2010. 230 f. Tese (Doutorado em Fitotecnia) - Universidade Federal do Ceará, Fortaleza.

PATANÈ, C.; CAVAllaro, V.; COSENTINO, S. L. Germination and radicle growth in unprimed and primed seeds of sweet sorghum as affected by reduced water potential in $\mathrm{NaCl}$ at different temperatures. Industrial Crops and Products, v. 30, n. 01, p. 01-08, 2009.

SILVA, T. R. G.; CORTELAZZO, A. L.; DIETRICH, S. M. C. Cytological aspects of storage mobilization in seeds of Dalbergia miscolobium during germination and plantlet growth. Ciência e Cultura, v. 49, n. 03, p. 170-176, 1997.

SILVA, R. N. et al. Composição química de sementes de trigo (Triticum aestivum L.) submetidas a estresse salino na germinação. Revista Brasileira de Sementes, v. 30, n. 01, p. 215-220, 2008.

SOLTANI, A.; GHOLIPOOR, M.; ZEINALI, E. Seed reserve utilization and seedling growth of wheat as affected by drought and salinity. Environmental and Experimental Botany, v. 55, n. 01/02, p. 195-200, 2006.

TEIXEIRA, S. P.; MACHADO, S. R. Storage sites in seeds of Caesalpinia echinata and C. ferrea (leguminosae) with considerations on nutrients flow. Brazilian Archives of Biology and Technology, v. 51, n. 01, p. 127-136, 2008.

VIDAL, B. C. Dichroism in collagen bundles stained with xylidine Ponceau 2R. Annalytical Histochemistry, v. 15. n. 04, p. 289-296, 1970. 
VIDAL B. C. Acid glycosaminoglycans and endochondral ossification: microspectrophotometric evaluation and macromolecular orientation. Cell Molecular Biology, v. 22, n. 01, p. 45- 64, 1977.
WINDAUER, L.; ALTUNA, A.; BENECH-ARNOLD, R. Hydrotime analysis of Lesquerella fendleri seed germination responses to priming treatments. Industrial Crops and Products, v. 25, n. 01, p. 70-74, 2007. 